\title{
Reduced Exposure to Calcineurin Inhibitors in Renal Transplantation
}

\author{
Henrik Ekberg, M.D., Ph.D., Helio Tedesco-Silva, M.D., Alper Demirbas, M.D., \\ Štefan Vítko, M.D., Björn Nashan, M.D., Ph.D., Alp Gürkan, M.D., F.A.C.S., \\ Raimund Margreiter, M.D., Christian Hugo, M.D., Josep M. Grinyó, M.D., \\ Ulrich Frei, M.D., Yves Vanrenterghem, M.D., Ph.D., Pierre Daloze, M.D., \\ and Philip F. Halloran, M.D., Ph.D., for the ELITE-Symphony Study**
}

ABSTRACT

From Lund University, Malmö, Sweden (H.E.); Federal University, São Paulo (H.T.-S.); Akdeniz University, Antalya, Turkey (A.D.); Institutu Klinické a Experimentální Medicíny, Prague, Czech Republic (S.V.); Medizinische Hochschule, Hannover, Germany (B.N.); S.B. Tepecik Hospital, Izmir, Turkey (A.G.); Universitaetsklinik, Innsbruck, Austria (R.M.); University Hospital, Erlangen, Germany (C.H.); Ciutat Universitaria de Bellvitge, Barcelona (J.M.G.); Charité, Virchow-Klinikum, Berlin (U.F.); Katholieke Universiteit Leuven, Leuven, Belgium (Y.V.); NotreDame Hospital, Centre Hospitalier de I'Université de Montréal, Montreal (P.D.); and University of Alberta, Edmonton, Canada (P.F.H.). Address reprint requests to Dr. Ekberg at the Department of Nephrology and Transplantation, University Hospital, 20503 Malmö, Sweden, or at henrik. ekberg@med.lu.se.

*Investigators who participated in the Efficacy Limiting Toxicity Elimination (ELITE)-Symphony study are listed in the Appendix.

N EnglJ Med 2007;357:2562-75.

Copyright (C) 2007 Massachusetts Medical Society.

\section{BACKGROUND}

Immunosuppressive regimens with the fewest possible toxic effects are desirable for transplant recipients. This study evaluated the efficacy and relative toxic effects of four immunosuppressive regimens.

\section{METHODS}

We randomly assigned 1645 renal-transplant recipients to receive standard-dose cyclosporine, mycophenolate mofetil, and corticosteroids, or daclizumab induction, mycophenolate mofetil, and corticosteroids in combination with low-dose cyclosporine, low-dose tacrolimus, or low-dose sirolimus. The primary end point was the estimated glomerular filtration rate (GFR), as calculated by the Cockcroft-Gault formula, 12 months after transplantation. Secondary end points included acute rejection and allograft survival.

\section{RESULTS}

The mean calculated GFR was higher in patients receiving low-dose tacrolimus (65.4 $\mathrm{ml}$ per minute) than in the other three groups (range, 56.7 to $59.4 \mathrm{ml}$ per minute). The rate of biopsy-proven acute rejection was lower in patients receiving low-dose tacrolimus (12.3\%) than in those receiving standard-dose cyclosporine $(25.8 \%)$, lowdose cyclosporine (24.0\%), or low-dose sirolimus (37.2\%). Allograft survival differed significantly among the four groups $(\mathrm{P}=0.02)$ and was highest in the low-dose tacrolimus group (94.2\%), followed by the low-dose cyclosporine group (93.1\%), the standard-dose cyclosporine group (89.3\%), and the low-dose sirolimus group (89.3\%). Serious adverse events were more common in the low-dose sirolimus group than in the other groups (53.2\% vs. a range of 43.4 to $44.3 \%$ ), although a similar proportion of patients in each group had at least one adverse event during treatment (86.3 to $90.5 \%$ ).

\section{CONCLUSIONS}

A regimen of daclizumab, mycophenolate mofetil, and corticosteroids in combination with low-dose tacrolimus may be advantageous for renal function, allograft survival, and acute rejection rates, as compared with regimens containing daclizumab induction plus either low-dose cyclosporine or low-dose sirolimus or with standard-dose cyclosporine without induction. (ClinicalTrials.gov number, NCT00231764.) 
ESPITE IMPROVED SHORT-TERM OUTcome in renal transplantation, 3 to $5 \%$ of allografts per year are still lost; the leading causes are long-term allograft nephropathy and death with a functioning allograft. ${ }^{1}$ As patients have fewer acute rejection episodes, adverse events associated with long-term immunosuppression have become increasingly evident. Accordingly, reducing the toxic effects of immunosuppressive regimens has become a major goal in the treatment of transplant recipients.

Cyclosporine, a calcineurin inhibitor in use for many years, is still the basis of many immunosuppressive regimens because of its clinical success. However, standard recommended doses are associated with nephrotoxicity, resulting in long-term renal dysfunction, ${ }^{2}$ hypertension, and hyperlipidemia. $^{3-6}$ In one report, virtually all 99 recipients of kidney-pancreas transplants who received cyclosporine-based immunosuppression had nephrotoxicity 10 years after transplantation, with the median onset of the first lesion at 6 months. ${ }^{7}$ Tacrolimus, a more recently introduced calcineurin inhibitor, is reportedly more effective than cyclosporine at improving allograft survival and preventing acute rejection at 1 year. ${ }^{8}$ However, at currently recommended doses, tacrolimus shares many side effects with cyclosporine, including nephrotoxicity, neurotoxicity, infectious complications, and disturbances in lipid metabolism. ${ }^{9,10}$ Sirolimus, recently introduced, is as effective as cyclosporine ${ }^{11,12}$ but is associated with delayed wound healing, ${ }^{13}$ formation of lymphoceles, ${ }^{14}$ and an increased incidence of several other adverse events (including hyperlipidemia, ${ }^{11}$ thrombocytopenia, ${ }^{12}$ and diarrhea), as compared with cyclosporine. $^{12}$

Accordingly, immunosuppressive regimens that would permit dose reductions of these calcineurin inhibitors and sirolimus would be attractive, provided that adequate immunosuppression and acceptable rates of acute rejection were preserved. The Efficacy Limiting Toxicity Elimination (ELITE)Symphony study was initiated to assess whether a mycophenolate mofetil-based regimen would permit the administration of lower doses of adjunct immunosuppressive agents (e.g., cyclosporine, tacrolimus, and sirolimus), yet still maintain an acceptable rate of acute rejection and a more favorable tolerability profile. Unlike many other studies that have evaluated immunosuppressive regimens, our trial used low-dose maintenance levels of cyclosporine, tacrolimus, or sirolimus from the day of transplantation. The study design was based on standard clinical procedures in common use internationally, a factor that allowed many patients to meet the criteria for study entry.

\section{METHODS}

\section{STUDY DESIGN AND PATIENTS}

We carried out a 12-month, prospective, randomized, open-label, multicenter study in four parallel groups of adult renal-transplant recipients in compliance with the provisions of the Declaration of Helsinki and Good Clinical Practice guidelines. All patients provided written informed consent and could withdraw from the study at any time.

The trial was proposed and designed by the first and last authors, who obtained funding and ran the trial, along with steering committee members, who had complete access to the data for review of the analysis and controlled the decision to publish. Funding for the study was provided by Hoffmann-La Roche, which had advisory input into the study design, collected the data, monitored the conduct of the study, performed the statistical analyses, and coordinated the writing of the manuscript with all authors. The first author had access to the complete study data, and vouches for the veracity and completeness of the data and the data analyses. Representatives of Hoffmann-La Roche had the opportunity to review and comment on all versions of the manuscript.

Patients between the ages of 18 and 75 years who were scheduled to receive a single-organ renal transplant from either a living donor or a deceased donor were eligible. Patients receiving a second renal transplant were eligible, provided that the first allograft was not lost owing to acute rejection within the first year after transplantation. Exclusion criteria included the need for treatment with azathioprine, methotrexate or cyclophosphamide, polyclonal or monoclonal antilymphocyte antibodies, basiliximab, or any investigational drug; a current or historic panel-reactive antibody titer of more than $20 \%$; a positive cross-match; a coldischemia time of more than 30 hours for the allograft; receipt of an allograft from a deceased donor without a heartbeat; a gastrointestinal disorder that might interfere with the ability to ab- 
sorb oral medication; a history of cancer, except successfully treated, localized nonmelanocytic skin cancer; active peptic ulcer; evidence of active liver disease; severe anemia, leukopenia, or thrombocytopenia; the receipt of a new investigational drug within the previous 3 months; and previous treatment with daclizumab or basiliximab.

Patients were randomly assigned in a 1:1:1:1 ratio to one of four treatment groups: the standard-dose cyclosporine group, which received a standard dose of cyclosporine (Neoral or Sandimmune, Novartis), mycophenolate mofetil (CellCept, Hoffmann-La Roche), and corticosteroids; the lowdose cyclosporine group, which received daclizumab (Zenapax, Hoffmann-La Roche) during the first 2 months after transplantation and a low dose of cyclosporine, mycophenolate mofetil, and corticosteroids; the low-dose tacrolimus group, which received daclizumab during the first 2 months after transplantation and a low dose of tacrolimus (Prograf, Astellas Pharma), mycophenolate mofetil, and corticosteroids; and the low-dose sirolimus group, which received daclizumab during the first 2 months after transplantation and a low dose of sirolimus (Rapamune, Wyeth), mycophenolate mofetil, and corticosteroids.

Randomization was stratified according to the local participating center and the presence or absence of a donor with expanded criteria. ${ }^{15}$ Patients underwent randomization before scheduled renal transplantation with the use of a centralized interactive voice-response system (ClinIT). A minimization algorithm was used to optimize the balance of characteristics of patients in study groups, overall and across the strata.

Intravenous daclizumab was infused during a period of 15 to 20 minutes at a dose of $2 \mathrm{mg}$ per kilogram of body weight within 24 hours before transplantation, followed by four doses of $1 \mathrm{mg}$ per kilogram every 2 weeks. The first doses of mycophenolate mofetil, cyclosporine, tacrolimus, and sirolimus were administered within 24 hours before or after transplantation. All groups received oral mycophenolate mofetil at a dose of $2 \mathrm{~g}$ per day. In the standard-dose cyclosporine group, the initial oral dose of 3 to $5 \mathrm{mg}$ per kilogram twice daily was adjusted to achieve a target trough level of 150 to $300 \mathrm{ng}$ per milliliter for the first 3 months and 100 to $200 \mathrm{ng}$ per milliliter thereafter. Target trough cyclosporine levels in the lowdose cyclosporine group were 50 to $100 \mathrm{ng}$ per milliliter throughout the study; the initial oral dose was 1 to $2 \mathrm{mg}$ per kilogram twice daily. In the low-dose tacrolimus group, the initial dose of oral tacrolimus of $0.1 \mathrm{mg}$ per kilogram per day divided into two daily doses was adjusted to achieve a target trough level of 3 to 7 ng per milliliter. In the low-dose sirolimus group, patients received oral sirolimus at a dose of $9 \mathrm{mg}$ per day for 3 days and $3 \mathrm{mg}$ per day thereafter, adjusted to achieve trough levels of 4 to 8 ng per milliliter. All patients received intraoperative and maintenance corticosteroids according to the practice at the center. The minimum maintenance corticosteroid doses were $20 \mathrm{mg}$ of prednisone (or the equivalent) for the first 2 weeks after transplantation, $15 \mathrm{mg}$ from week 3 to week $8,10 \mathrm{mg}$ from week 9 until the end of month 4, and $5 \mathrm{mg}$ thereafter.

Blood levels of cyclosporine, tacrolimus, and sirolimus were measured with the use of locally available assays. On the basis of information from 60 of 83 sites, the most commonly used assays were TDx (Abbott Diagnostics) for cyclosporine (used at 33.3\% of sites), IMx (Abbott Diagnostics) for tacrolimus (used by $65.0 \%$ ), and high-performance liquid chromatography with ultraviolet detection for sirolimus (used by 61.7\%).

\section{EFFICACY}

The primary end point was the estimated glomerular filtration rate (GFR) 12 months after transplantation, calculated from serum creatinine measures with the use of the Cockcroft-Gault formula. ${ }^{16}$ Secondary efficacy end points included renal function as indicated by the calculated GFR during the course of the study, measured GFR at 12 months, acute rejection, overall survival and allograft survival at 6 and 12 months, time to the first episode of acute rejection, the frequency of treatment failure during the first 12 months, and the incidence of delayed allograft function. Treatment failure was defined as the occurrence of any of the following: the use of additional immunosuppressive medication, the discontinuation of any study medication for more than 14 consecutive days or more than 30 cumulative days, allograft loss, or death.

\section{SAFETY}

Safety was evaluated by clinical assessment including vital signs and laboratory analyses designed to determine the incidence of adverse events, opportunistic infections, cancer, and death through- 
out the study; the incidence of failure to achieve primary closure of the transplant surgical wound at 2 weeks; and the formation of lymphoceles requiring intervention within 6 months after transplantation.

\section{STATISTICAL ANALYSIS}

The original protocol called for the enrollment of 1300 patients. In an amendment to the protocol, this number was increased to 1760 patients (440 per group) to provide a power of $80 \%$ to detect a difference of $6.5 \mathrm{ml}$ per minute in GFR in one group with respect to the others in a global test, a value that was considered to be clinically relevant by the study's steering committee. To calculate the GFR, a last-observation-carried-forward method was used for serum creatinine and weight, and $10 \mathrm{ml}$ per minute was imputed for missing values.

The primary method used to compare the study groups was an analysis of variance including factors for treatment, center, and donors with expanded criteria and other factors. Since the model, even after variable transformations, markedly violated the assumptions for normality (as judged by the study statistician after inspection of diagnostic plots and by the rejection of normality assumption with the use of the Shapiro-Wilk test at the $10 \%$ level), we performed overall group comparisons with the use of the Kruskal-Wallis test, followed by pairwise comparisons with the Wilcoxon rank-sum test in case of significance at the $5 \%$ level. Time to biopsy-proven acute rejection, allograft loss, treatment failure, and death were analyzed with the use of the Kaplan-Meier method, and group differences were assessed by the log-rank test.

Groups of patients that underwent analysis included a safety population (patients who received at least one dose of a study drug) and an intention-to-treat population (patients who received at least one dose of a study drug and underwent transplantation). Patients who were prematurely withdrawn from the study were followed for data collection whenever possible.

The incidence of all adverse events and serious adverse events are reported as frequencies in the safety population. However, the number of patients at risk for an event varied with time, owing to the variation in premature withdrawal in the study groups. Therefore, additional Kaplan-Meier analyses were performed for selected adverse events known to be associated with immunosuppressive drugs, ${ }^{9,12,14}$ including new-onset diabetes after transplantation, diarrhea, the formation of lymphoceles, opportunistic infections, and cytomegalovirus infection.

RESULTS

\section{PATIENTS}

From November 2002 to November 2004, a total of 1645 patients from 83 sites in 15 countries underwent randomization (Fig. 1). Although the recruitment target of 1760 was not met by the end of the planned enrollment period, the duration of recruitment was not extended for operational reasons. The groups were well balanced with respect to demographic, clinical, and donor-recipient characteristics, with no significant betweengroup differences (Table 1). Withdrawal from assigned treatment ranged from $20.0 \%$ in the lowdose tacrolimus group to $48.9 \%$ in the low-dose sirolimus group (Fig. 1). In all groups, treatment failure was the main reason for withdrawal. The use of additional immunosuppressive drugs (in 7.5 to $30.3 \%$ of patients, depending on the group) and the discontinuation of a study drug (in 16.4 to $24.6 \%$ of patients, depending on the group) were the main categories of treatment failure in the four study groups. Acute rejection was not explicitly included as one of the possible reasons for treatment failure.

Target trough levels for immunosuppression were generally met (Fig. 2). Mean ( $\pm S D$ ) levels were mainly at the upper end of the target range. Mean daily doses of corticosteroids (or prednisone equivalent) during the first year were $16.3 \pm 13.1$ $\mathrm{mg}$ (in the standard-dose cyclosporine group), $14.2 \pm 14.2 \mathrm{mg}$ (in the low-dose cyclosporine group), $13.5 \pm 10.0 \mathrm{mg}$ (in the low-dose tacrolimus group), and $17.7 \pm 14.1 \mathrm{mg}$ (in the low-dose sirolimus group). These doses were higher in the standarddose cyclosporine group and the low-dose sirolimus group than in the low-dose tacrolimus group $(\mathrm{P}=0.01$ and $\mathrm{P}<0.001$, respectively) and higher in the low-dose sirolimus group than in the low-dose cyclosporine group $(\mathrm{P}<0.001)$.

\section{EFFICACY MEASUREMENTS}

\section{GFR}

Twelve months after transplantation, renal function differed significantly among the four groups ( $\mathrm{P}<0.001$ for the overall group comparison). The 


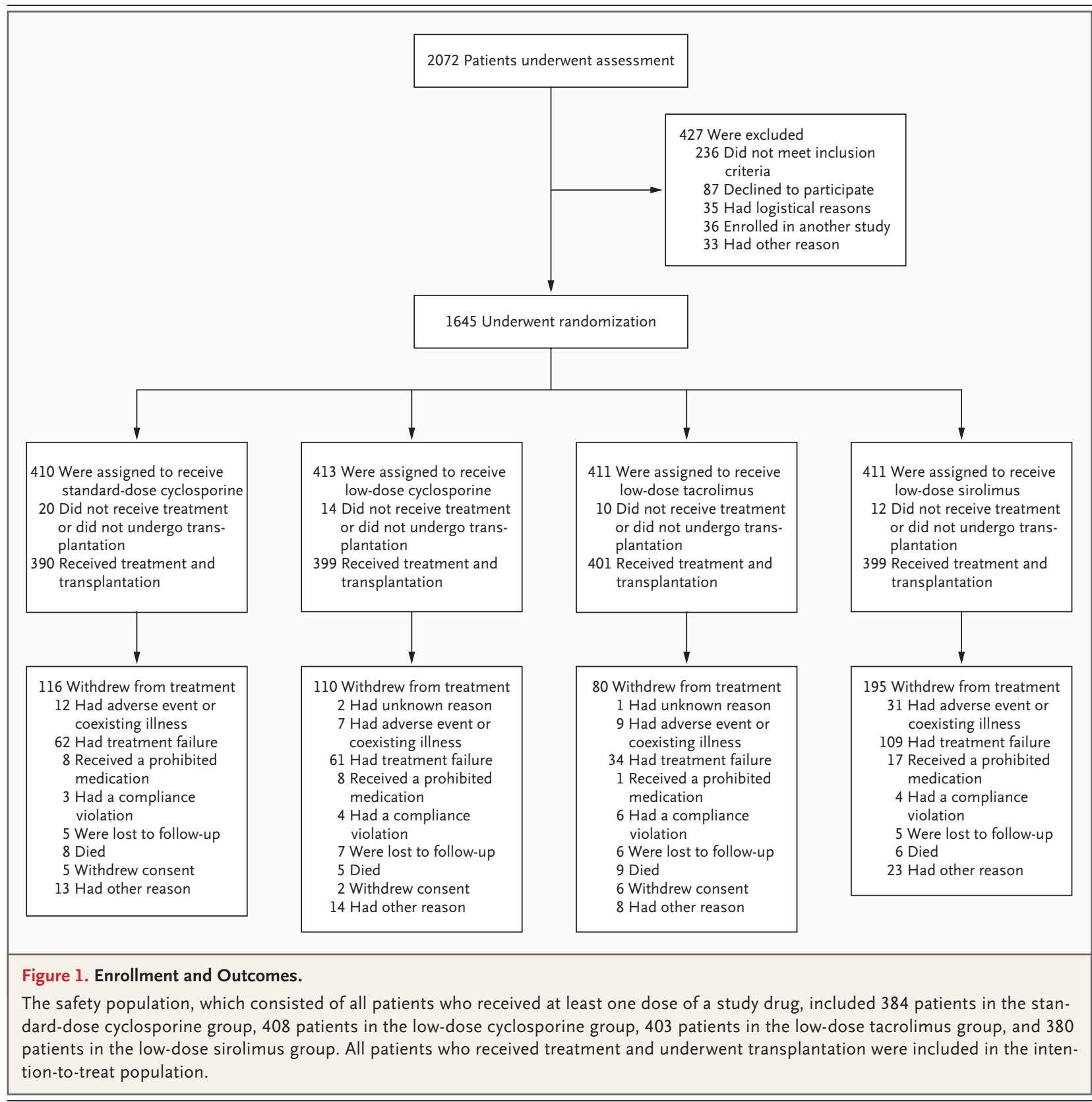

estimated GFR was higher in the low-dose tacrolimus group than in the other study groups $(\mathrm{P}<0.001$ for the comparisons with the standarddose cyclosporine group and the low-dose sirolimus group and $\mathrm{P}=0.001$ for the comparison with the low-dose cyclosporine group) (Table 2). The mean estimated GFR remained relatively stable from about 8 weeks onward.

\section{Acute Rejection}

At 6 and 12 months, the incidence of biopsy-proven acute rejection (excluding borderline cases) in the low-dose tacrolimus group was approximately half those in the standard-dose cyclosporine group and the low-dose cyclosporine group and approximately one third that in the low-dose sirolimus group $(\mathrm{P}<0.001$ for all pairwise comparisons with low- 


\begin{tabular}{|c|c|c|c|c|}
\hline Variable & $\begin{array}{c}\text { Standard-Dose } \\
\text { Cyclosporine } \\
(N=390)\end{array}$ & $\begin{array}{l}\text { Low-Dose } \\
\text { Cyclosporine } \\
(\mathrm{N}=399)\end{array}$ & $\begin{array}{l}\text { Low-Dose } \\
\text { Tacrolimus } \\
\text { (N=401) }\end{array}$ & $\begin{array}{c}\text { Low-Dose } \\
\text { Sirolimus } \\
(\mathrm{N}=399)\end{array}$ \\
\hline Age (yr) & $45.9 \pm 13.8$ & $47.2 \pm 13.5$ & $45.4 \pm 14.7$ & $44.9 \pm 14.5$ \\
\hline Male sex (\%) & 62.3 & 66.4 & 65.8 & 66.7 \\
\hline \multicolumn{5}{|l|}{ Race $(\%) \uparrow$} \\
\hline White & 92.1 & 92.2 & 94.0 & 94.2 \\
\hline Black & 2.1 & 2.3 & 1.0 & 1.3 \\
\hline Asian & 1.3 & 0.8 & 0.7 & 0.5 \\
\hline Other & 4.6 & 4.8 & 4.2 & 4.0 \\
\hline \multicolumn{5}{|l|}{ Cause of end-stage renal disease (\%) } \\
\hline Glomerulonephritis & 29.7 & 26.1 & 26.9 & 28.8 \\
\hline Diabetes mellitus & 6.9 & 9.0 & 8.5 & 7.8 \\
\hline Pyelonephritis or interstitial nephritis & 10.0 & 8.0 & 9.2 & 11.5 \\
\hline Polycystic kidney disease & 12.8 & 12.0 & 15.5 & 11.3 \\
\hline Uncertain & 19.5 & 24.3 & 20.7 & 19.0 \\
\hline Other & 20.5 & 20.3 & 19.2 & 21.3 \\
\hline Missing data & 0.5 & 0.3 & 0 & 0.3 \\
\hline \multicolumn{5}{|l|}{ Type of donor (\%) } \\
\hline Deceased & 65.6 & 64.2 & 62.8 & 64.2 \\
\hline Living related & 28.5 & 26.8 & 31.7 & 30.1 \\
\hline Living unrelated & 5.9 & 8.8 & 5.2 & 5.8 \\
\hline Donors with expanded criteria (\%) & 16.9 & 18.0 & 17.7 & 19.3 \\
\hline Donor age (yr) & $44.6 \pm 15.9$ & $46.2 \pm 15.1$ & $45.2 \pm 15.5$ & $46.0 \pm 14.8$ \\
\hline Antigen mismatches - A, B, and DR (no.) & $2.95 \pm 1.54$ & $3.05 \pm 1.50$ & $2.87 \pm 1.55$ & $2.99 \pm 1.49$ \\
\hline $\begin{array}{l}\text { Panel-reactive antibody }>0 \% \text { - most recent } \\
\text { assessment (\%) }\end{array}$ & 21.0 & 22.1 & 19.9 & 17.1 \\
\hline Cold-ischemia time - deceased donors only (hr) & $16.6 \pm 5.5$ & $16.8 \pm 5.2$ & $16.5 \pm 5.7$ & $16.0 \pm 5.8$ \\
\hline $\begin{array}{c}\text { Cytomegalovirus serologic status - donor posi- } \\
\text { tive, recipient negative (\%) }\end{array}$ & 13.6 & 13.5 & 12.7 & 15.5 \\
\hline
\end{tabular}

* Plus-minus values are means \pm SD. Between-group differences for demographic and clinical characteristics were not significant.

$\uparrow$ Race was determined by the investigator.

$¥$ The percentage is that of deceased donors only. Expanded criteria for deceased donors included an age of more than 60 years or an age of more than 50 years and at least two of the following factors: cerebovascular accident as the cause of death, hypertension, or a serum creatinine level of more than $1.5 \mathrm{mg}$ per deciliter (133 $\mu \mathrm{mol}$ per liter).

dose tacrolimus) (Fig. 3A and Table 2). At 12 months, the proportions of patients with clinically suspected, treated episodes of acute rejection were similar to those of biopsy-proven acute rejection $(\mathrm{P}<0.001$ for all pairwise comparisons with low-dose tacrolimus) (Table 2).

\section{OVERALL SURVIVAL AND ALLOGRAFT SURVIVAL}

Allograft survival in the low-dose tacrolimus group was significantly higher than in the standard-dose cyclosporine group and the low-dose sirolimus group ( $\mathrm{P}=0.007$ for both comparisons) (Table 2 and Fig. 3B). Overall survival rates for patients were more than $96 \%$ in all groups without significant differences (Table 2).

\section{TREATMENT FAILURE}

Treatment failure was lowest in the low-dose tacrolimus group (12.2\%) and highest in the lowdose sirolimus group $(35.8 \%, \mathrm{P}<0.001)$ (Table 2$)$. 


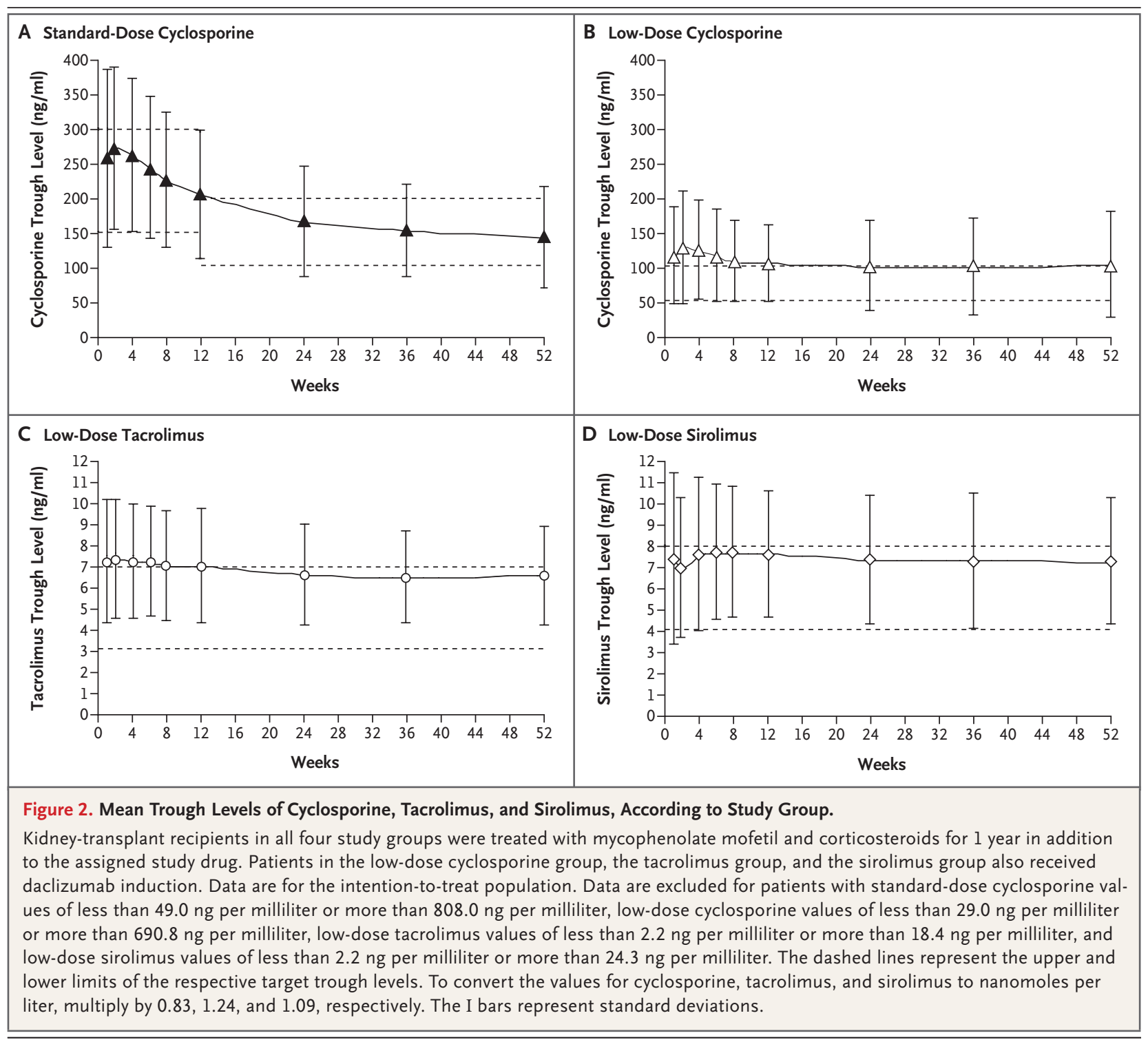

Treatment failure as a result of discontinuation of any assigned immunosuppressive agent for more than 14 consecutive days leading to withdrawal was $4.5 \%$ in the low-dose tacrolimus group, as compared with 5.1 to $6.8 \%$ in the other study groups. Treatment failure as a result of the use of additional maintenance immunosuppressive medication was $1.5 \%$ in the low-dose tacrolimus group, as compared with 6.0 to $14.8 \%$ in the other study groups. Overall, the rate of treatment failure was $44.0 \%$ in patients who had acute rejection, as compared with $13.7 \%$ in those who did not have acute rejection in the intention-to-treat population.

\section{DELAYED ALLOGRAFT FUNCTION}

Among recipients of a kidney from a deceased donor, the incidence of delayed allograft function at 2 weeks (defined as persistent oliguria, a decrease in the serum creatinine level of less than $0.5 \mathrm{mg}$ per deciliter within 24 hours after transplantation, or the institution of dialysis) was lower in the lowdose sirolimus group than in the low-dose tacrolimus group $(\mathrm{P}=0.001)$ (Table 2$)$.

\section{SAFETY}

Serious adverse events were reported by $53.2 \%$ of patients in the low-dose sirolimus group, as com- 
Table 2. Primary End Point and Selected Secondary End Points.*

\begin{tabular}{|c|c|c|c|c|c|}
\hline End Point & $\begin{array}{l}\text { Standard-Dose } \\
\text { Cyclosporine } \\
(\mathrm{N}=390)\end{array}$ & $\begin{array}{l}\text { Low-Dose } \\
\text { Cyclosporine } \\
(\mathrm{N}=399)\end{array}$ & $\begin{array}{l}\text { Low-Dose } \\
\text { Tacrolimus } \\
\text { (N=401) }\end{array}$ & $\begin{array}{l}\text { Low-Dose } \\
\text { Sirolimus } \\
(N=399)\end{array}$ & P Value'̀ \\
\hline \multicolumn{6}{|l|}{ Primary end point } \\
\hline Mean calculated GFR - ml/min & $57.1 \pm 25.1$ & $59.4 \pm 25.1$ & $65.4 \pm 27.0$ & $56.7 \pm 26.9$ & $<0.001$ \\
\hline$P$ value for comparison with tacrolimus & $<0.001$ & 0.001 & Reference & $<0.001$ & \\
\hline \multicolumn{6}{|l|}{ Secondary end points } \\
\hline Mean measured GFR — ml/min $\sqrt{ }$ & $63.5 \pm 25.4$ & $65.3 \pm 26.6$ & $69.6 \pm 27.9$ & $64.4 \pm 28.5$ & 0.04 \\
\hline P value for comparison with tacrolimus & 0.01 & 0.10 & Reference & 0.02 & \\
\hline Mean calculated GFR - ml/min 9 & $46.2 \pm 23.1$ & $50.2 \pm 23.1$ & $54.3 \pm 23.9$ & $47.5 \pm 26.1$ & $<0.001$ \\
\hline P value for comparison with tacrolimus & $<0.001$ & 0.007 & Reference & $<0.001$ & \\
\hline \multicolumn{6}{|l|}{ Acute rejection $\|$} \\
\hline \multicolumn{6}{|l|}{ At 6 mo } \\
\hline Biopsy-proven (excluding borderline values) — \% & 24.0 & 21.9 & 11.3 & 35.3 & $<0.001$ \\
\hline$P$ value for comparison with tacrolimus & $<0.001$ & $<0.001$ & Reference & $<0.001$ & \\
\hline \multicolumn{6}{|l|}{ At $12 \mathrm{mo}$} \\
\hline Suspected and treated — \% & 32.8 & 29.5 & 17.2 & 43.5 & $<0.001$ \\
\hline$P$ value for comparison with tacrolimus & $<0.001$ & $<0.001$ & Reference & $<0.001$ & \\
\hline Biopsy-proven (including borderline values) — \% & 30.1 & 27.2 & 15.4 & 40.2 & $<0.001$ \\
\hline$P$ value for comparison with tacrolimus & $<0.001$ & $<0.001$ & Reference & $<0.001$ & \\
\hline Biopsy-proven (excluding borderline values) — \% & 25.8 & 24.0 & 12.3 & 37.2 & $<0.001$ \\
\hline$P$ value for comparison with tacrolimus & $<0.001$ & $<0.001$ & Reference & $<0.001$ & \\
\hline Antibody treated — \% & 6.3 & 4.7 & 2.3 & 6.6 & 0.01 \\
\hline P value for comparison with tacrolimus & 0.006 & 0.08 & Reference & 0.005 & \\
\hline \multicolumn{6}{|l|}{ Allograft survival\| } \\
\hline $\begin{array}{l}\text { Censored for death of patients with functioning } \\
\text { allograft — \% }\end{array}$ & 91.9 & 94.3 & 96.4 & 91.7 & 0.02 \\
\hline$P$ value for comparison with tacrolimus & 0.007 & 0.18 & Reference & 0.007 & \\
\hline $\begin{array}{l}\text { Uncensored for death of patients with functioning } \\
\quad \text { allograft — \% }\end{array}$ & 89.3 & 93.1 & 94.2 & 89.3 & 0.02 \\
\hline P value for comparison with tacrolimus & 0.01 & 0.56 & Reference & 0.01 & \\
\hline Patient survival — \%\| & 96.5 & 98.2 & 97.2 & 96.8 & 0.53 \\
\hline $\mathrm{P}$ value for comparison with tacrolimus & 0.60 & 0.35 & Reference & 0.78 & \\
\hline Treatment failure — \%\| & 22.8 & 20.1 & 12.2 & 35.8 & $<0.001$ \\
\hline$P$ value for comparison with tacrolimus & $<0.001$ & 0.003 & Reference & $<0.001$ & \\
\hline Delayed allograft function (deceased donors only) — \% & 33.6 & 32.4 & 35.7 & 21.1 & 0.004 \\
\hline$P$ value for comparison with tacrolimus & 0.73 & 0.51 & Reference & 0.001 & \\
\hline
\end{tabular}

* Plus-minus values are means \pm SD. P values for comparisons between each of the study groups and the low-dose tacrolimus group were calculated with the use of the Wilcoxon rank-sum test for end points regarding the glomerular filtration rate (GFR) and the log-rank test for all other end points except delayed allograft function, for which the chi-square test was used.

$\uparrow P$ values were calculated with the use of the Kruskal-Wallis test for the overall group comparison.

The calculated GFR (with an imputation of $10 \mathrm{ml}$ per minute for missing values and the last observation carried forward) was determined from the serum creatinine level with the use of the Cockcroft-Gault formula to calculate creatinine clearance. The number of patients with the last observation carried forward and imputed values for calculated GFR were 23 and 37, respectively, in the standard-dose cyclosporine group (15.4\%), 22 and 25 in the low-dose cyclosporine group (11.8\%), 19 and 24 in the low-dose tacrolimus group (10.7\%), and 27 and 38 in the low-dose sirolimus group (16.3\%).

$\int$ The GFR was measured at 12 months mostly by the 24-hour urine method.

If For the calculated GFR on the basis of abbreviated Modification of Diet in Renal Disease criteria, the following formula was used: estimated GFR $\left(\mathrm{ml} / \mathrm{min} / 1.73 \mathrm{~m}^{2}\right)=186 \times(\text { serum creatinine })^{-1.154} \times(\text { age })^{-0.203} \times(0.742$ if female $) \times(1.21$ if black $)$.

|| Values are Kaplan-Meier estimates over time. 


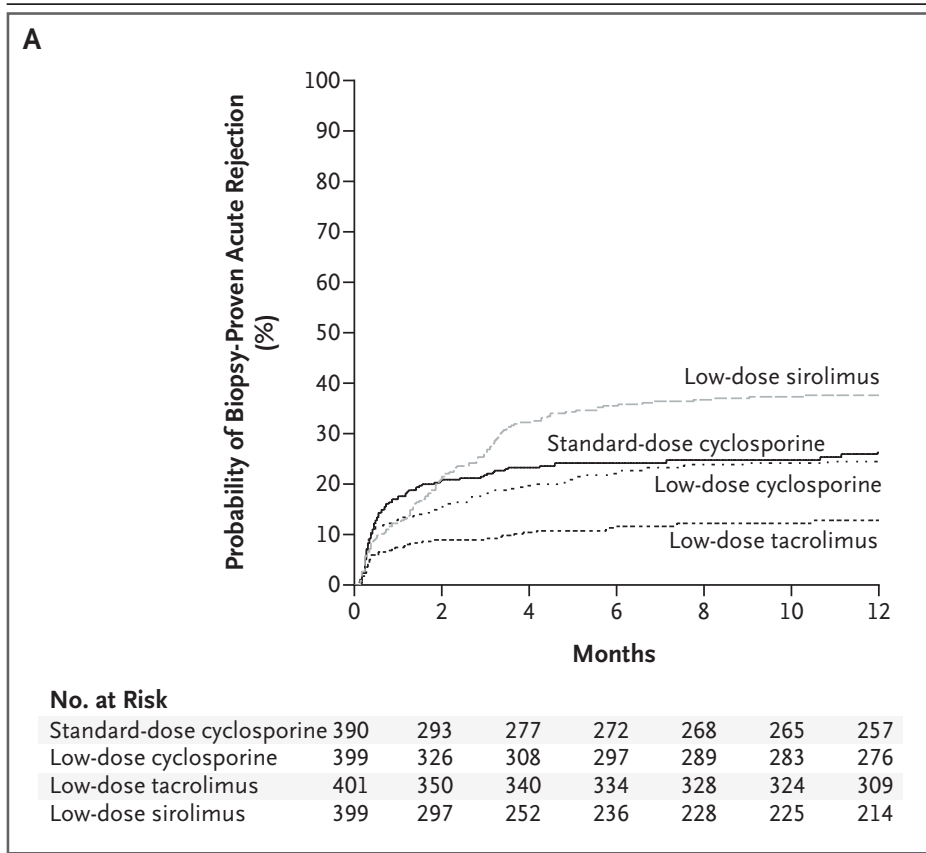

B

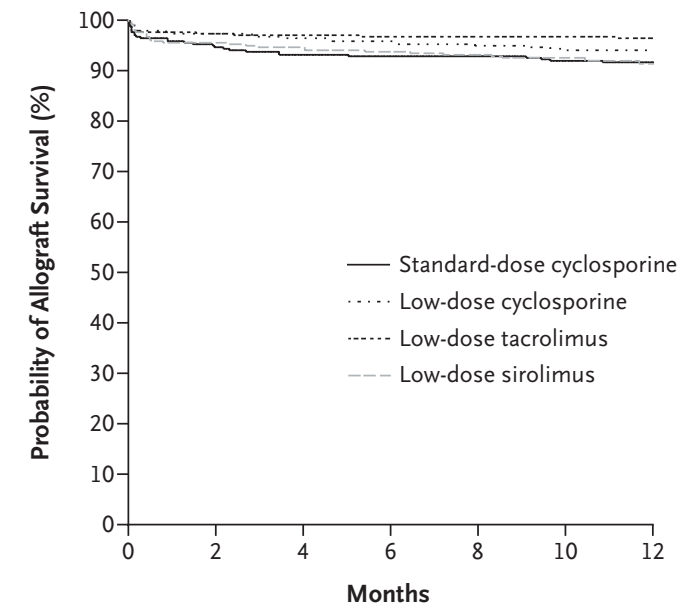

No. at Risk

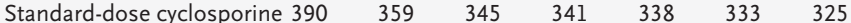
$\begin{array}{llllllll}\text { Low-dose cyclosporine } & 399 & 381 & 371 & 367 & 363 & 355 & 345\end{array}$ $\begin{array}{llllllll}\text { Low-dose tacrolimus } & 401 & 381 & 374 & 371 & 367 & 363 & 349\end{array}$

$\begin{array}{llllllll}\text { Low-dose sirolimus } & 399 & 373 & 364 & 358 & 349 & 344 & 329\end{array}$

Figure 3. Cumulative Probability of Biopsy-Proven Acute Rejection (Panel A) and Allograft Survival (Panel B), According to Study Group.

The number at risk at 12 months includes all patients who were not lost to follow-up and who had completed the 12-month visit not earlier than 2 weeks before the end of the first year after transplantation. For the Kaplan-Meier estimates of event rates presented here, data for patients who completed the study according to protocol before the first year after transplantation were censored at the time of their last visit. Data for patients with borderline acute rejection were excluded from the analysis of biopsy-proven acute rejection. The analysis of data for patients who died with a functioning allograft were censored. pared with 43.4 to $44.3 \%$ in the other study groups $(\mathrm{P}<0.05$ for all comparisons and for betweengroup comparisons with low-dose sirolimus). In a similar way, $7.8 \%$ of patients in the low-dose sirolimus group withdrew from treatment because of an adverse event or a coexisting illness, as compared with 1.8 to $3.1 \%$ in the other study groups (Fig. 1). A similar proportion of patients in each group had at least one adverse event during the study (86.3 to $90.5 \%)$.

The most common adverse events according to body system for all groups were disorders of the blood or lymphatic systems, gastrointestinal disorders, infections or infestations, and metabolism and nutrition disorders (Table 3).

There was a significant between-group difference in the Kaplan-Meier estimates for newonset diabetes after transplantation at 12 months ( $\mathrm{P}=0.02$ for all comparisons), with the highest rate occurring in the low-dose tacrolimus group (Table 3). The proportion of patients who required antidiabetes medication at 3 months after the onset of diabetes ranged from 1.0 to $2.7 \%$, depending on the study group. The Kaplan-Meier estimates for diarrhea differed significantly between the groups $(\mathrm{P}<0.001)$, with the lowest rates occurring in the two cyclosporine groups. With respect to the formation of lymphoceles, the rates also differed significantly among the groups $(\mathrm{P}<0.001)$, with at least twice as many events in the lowdose sirolimus group as in the other groups. In addition, the proportion of patients who had delayed wound healing 2 weeks after transplantation differed significantly among the study groups ( $\mathrm{P}=0.006$ by the chi-square test), with more patients in the low-dose sirolimus group having delayed healing than in the other groups (Table 3).

There was a significant between-group difference in the Kaplan-Meier estimates for opportunistic infections $(\mathrm{P}=0.03)$ and cytomegalovirus infection $(P=0.003)$, the latter being the most common opportunistic infection (Table 3). Opportunistic infections, including cytomegalovirus infection, were generally more common in the standard-dose cyclosporine group than in the other groups. Although there was no stratification according to donor-recipient status for cytomegalovirus, there was no significant between-group difference in the proportion of cytomegalovirus-positive donors to cytomegalovirusnegative patients (Table 1). 
Cancer developed in four to nine patients in the various study groups within the first 12 months (Table 3). There were 13 deaths in the standarddose cyclosporine group, and 7, 11, and 12 deaths in the low-dose cyclosporine group, the low-dose tacrolimus group, and the low-dose sirolimus group, respectively. Deaths were preceded by treatment failure in one patient in the standard-dose cyclosporine group, two patients in the low-dose cyclosporine group, one patient in the low-dose tacrolimus group, and one patient in the lowdose sirolimus group. Four deaths were caused by adverse events or coexisting illnesses: two in the standard-dose cyclosporine group and one each in the low-dose cyclosporine group and the low-dose tacrolimus group.

\section{DISCUSSION}

The primary objective of our study was to reduce nephrotoxicity with the use of low doses of calcineurin inhibitors or sirolimus. Accordingly, the primary end point was renal function. Secondary objectives were to reduce overall toxic effects while maintaining efficacy in terms of acute rejection, overall survival of patients, and allograft survival.

In an initial trial conducted by members of our group, the avoidance of calcineurin inhibitors with the use of mycophenolate mofetil, daclizumab, and corticosteroids resulted in excellent rates of overall and allograft survival at 12 months $(97 \%$ and $96 \%$, respectively) but had an unacceptably high rate of biopsy-proven acute rejection (53\%). ${ }^{17}$ Accordingly, the subsequent Cyclosporine Avoidance Eliminates Serious Adverse Renal Toxicity (CAESAR) study was designed with the addition of low-dose cyclosporine, either continuously administered or tapered and withdrawn at 4 to 6 months. ${ }^{18}$

Our findings represent a further development of strategies for reducing the burden of side effects. With the addition not only of low-dose cyclosporine but also of either low-dose tacrolimus or low-dose sirolimus to the combination of daclizumab, mycophenolate mofetil, and corticosteroids, our study aimed to reduce the rate of biopsy-proven acute rejection from the previously reported rate of $53 \% .{ }^{17}$ In both the CAESAR study $^{18}$ and our study, patients receiving low-dose cyclosporine had rates of biopsy-proven acute rejec- tion and of mean GFR at 12 months similar to those of patients receiving standard-dose cyclosporine. Thus, reduced doses of cyclosporine did not improve renal function, and further reductions in cyclosporine exposure (to trough levels $<50 \mathrm{ng}$ per milliliter) would probably not provide adequate immunosuppression. However, it is possible that optimizing the exposure to mycophenolate mofetil through therapeutic drug monitoring could improve rates of acute rejection and allograft function in a cyclosporine-based regimen.

In our study, the low-dose sirolimus regimen resulted in rates of biopsy-proven acute rejection that were higher than those in the other regimens, and there was no improvement in renal function, as compared with the cyclosporine-containing regimens. This latter result contrasts with the findings of Flechner et al., ${ }^{19}$ which showed no significant differences in efficacy but significantly better rates of renal function at 2 years and lower rates of long-term allograft nephropathy in patients receiving standard-dose sirolimus than in those receiving standard-dose cyclosporine, both in combination with basiliximab induction, mycophenolate mofetil, and corticosteroids. However, the study by Flechner et al. was a single-center study involving only 61 patients who received higher doses of sirolimus (trough level, 10 to $12 \mathrm{ng}$ per milliliter during the first 6 months and 5 to $10 \mathrm{ng}$ per milliliter thereafter) than did patients in our study (trough level, 4 to 8 ng per milliliter). It is possible that the sirolimus dose in our study was too low to provide adequate immunosuppression in the period immediately after transplantation. Nonetheless, biopsy-proven acute rejection did not reach the $53 \%$ level seen with the protocol calling for the administration of daclizumab, mycophenolate mofetil, and corticosteroids. ${ }^{17}$ Therefore, the addition of low-dose sirolimus had some efficacy, even though it did not eliminate side effects. It is also possible that the combination of sirolimus and mycophenolate mofetil is inadequate for preventing acute rejection. Two multicenter studies in renal-transplant patients receiving standard doses of sirolimus, mycophenolate mofetil, and corticosteroids, used in combination with interleukin-2 receptor antibody induction, were recently terminated early because of an increased risk of rejection. ${ }^{20}$

New-onset diabetes is an important concern after organ transplantation and appears to be re- 


\begin{tabular}{|c|c|c|c|c|}
\hline \multirow[t]{2}{*}{ Event } & $\begin{array}{l}\text { Standard-Dose } \\
\text { Cyclosporine } \\
(\mathrm{N}=384)\end{array}$ & $\begin{array}{l}\text { Low-Dose } \\
\text { Cyclosporine } \\
(\mathrm{N}=408)\end{array}$ & $\begin{array}{c}\text { Low-Dose } \\
\text { Tacrolimus } \\
\text { (N=403) }\end{array}$ & $\begin{array}{c}\text { Low-Dose } \\
\text { Sirolimus } \\
(\mathrm{N}=380)\end{array}$ \\
\hline & \multicolumn{4}{|c|}{ percent } \\
\hline \multicolumn{5}{|l|}{ Adverse event } \\
\hline Blood or lymphatic & 33.3 & 33.6 & 36.2 & 36.1 \\
\hline Anemia & 18.5 & 17.4 & 17.1 & 25.0 \\
\hline Leukopenia & 10.2 & 10.1 & 13.4 & 10.3 \\
\hline Gastrointestinal & 33.3 & 32.6 & 41.4 & 34.7 \\
\hline Abdominal pain & 3.9 & 4.2 & 5.2 & 2.6 \\
\hline Constipation & 6.5 & 5.2 & 6.7 & 6.1 \\
\hline Diarrhea & 15.6 & 13.0 & 25.3 & 19.5 \\
\hline Vomiting & 4.7 & 3.9 & 5.5 & 2.6 \\
\hline General or site of drug administration & 23.2 & 22.6 & 22.1 & 27.4 \\
\hline Peripheral edema & 12.0 & 12.5 & 11.2 & 13.2 \\
\hline Pyrexia & 4.4 & 5.6 & 5.0 & 9.0 \\
\hline Opportunistic infection† & 26.0 & 22.8 & 19.9 & 20.3 \\
\hline Candida & 7.6 & 4.7 & 3.0 & 5.0 \\
\hline Cytomegalovirus & 14.3 & 11.0 & 9.7 & 6.1 \\
\hline Herpes simplex virus & 5.5 & 3.7 & 4.5 & 6.1 \\
\hline Other infection or infestation & 54.2 & 50.5 & 52.4 & 52.6 \\
\hline Nasopharyngitis & 5.7 & 7.8 & 7.9 & 4.0 \\
\hline Pneumonia & 4.7 & 1.2 & 3.2 & 5.0 \\
\hline Urinary tract infection & 28.4 & 23.8 & 23.6 & 23.2 \\
\hline Injury, poisoning, or procedural complication & 32.6 & 27.2 & 26.8 & 31.1 \\
\hline Complications of transplanted kidney & 6.3 & 6.6 & 5.2 & 4.5 \\
\hline Delayed wound healing at week 2 & 10.8 & 11.0 & 9.4 & 16.6 \\
\hline Lymphocele & 6.3 & 5.6 & 4.0 & 11.6 \\
\hline Laboratory investigation & 24.5 & 24.8 & 26.8 & 25.5 \\
\hline Increased blood creatinine level & 7.8 & 6.9 & 8.2 & 7.9 \\
\hline Metabolism or nutrition & 46.1 & 38.2 & 38.0 & 47.1 \\
\hline Diabetes mellitus & 6.0 & 4.2 & 8.4 & 6.6 \\
\hline Hypercholesterolemia & 10.4 & 9.8 & 4.5 & 10.3 \\
\hline Hyperglycemia & 4.4 & 2.9 & 4.7 & 5.0 \\
\hline Hyperlipidemia & 14.8 & 12.5 & 9.9 & 15.8 \\
\hline Hypertriglyceridemia & 4.2 & 3.7 & 3.5 & 6.8 \\
\hline Hyperuricemia & 5.7 & 5.6 & 4.5 & 1.6 \\
\hline Hypophosphatemia & 3.1 & 3.7 & 3.5 & 5.5 \\
\hline Nervous system & 13.0 & 9.8 & 15.9 & 9.0 \\
\hline Headache & 5.0 & 4.2 & 5.5 & 3.2 \\
\hline Renal or urinary & 28.7 & 27.9 & 29.8 & 29.0 \\
\hline Hematuria & 5.2 & 4.9 & 5.2 & 4.2 \\
\hline Proteinuria & 2.3 & 2.0 & 5.0 & 5.3 \\
\hline
\end{tabular}

The New England Journal of Medicine

Downloaded from nejm.org at UNIVERSITAT DE BARCELONA CRAI on July 3, 2014. For personal use only. No other uses without permission. Copyright @ 2007 Massachusetts Medical Society. All rights reserved. 


\begin{tabular}{|c|c|c|c|c|}
\hline \multirow[t]{2}{*}{ Event } & $\begin{array}{l}\text { Standard-Dose } \\
\text { Cyclosporine } \\
(N=384)\end{array}$ & $\begin{array}{l}\text { Low-Dose } \\
\text { Cyclosporine } \\
(\mathrm{N}=408)\end{array}$ & $\begin{array}{c}\text { Low-Dose } \\
\text { Tacrolimus } \\
\text { (N=403) }\end{array}$ & $\begin{array}{c}\text { Low-Dose } \\
\text { Sirolimus } \\
(\mathrm{N}=380)\end{array}$ \\
\hline & \multicolumn{4}{|c|}{ percent } \\
\hline Vascular & 28.9 & 22.6 & 23.6 & 29.2 \\
\hline Hypertension & 14.3 & 11.5 & 12.9 & 11.8 \\
\hline \multicolumn{5}{|l|}{ Serious adverse event } \\
\hline Blood or lymphatic & 1.8 & 3.4 & 3.0 & 4.2 \\
\hline Cardiac & 3.9 & 3.7 & 3.2 & 2.9 \\
\hline Gastrointestinal & 3.9 & 5.6 & 8.2 & 7.6 \\
\hline General or site of drug administration & 1.3 & 2.5 & 3.0 & 5.3 \\
\hline Immune system & 1.6 & 2.7 & 1.5 & 3.4 \\
\hline Infection or infestation & 15.1 & 14.0 & 14.9 & 20.5 \\
\hline Injury, poisoning, or procedural complication & 11.2 & 8.8 & 9.7 & 11.1 \\
\hline Laboratory investigation & 3.7 & 2.9 & 6.2 & 5.5 \\
\hline Metabolism or nutrition & 2.1 & 2.5 & 3.5 & 3.7 \\
\hline Renal or urinary & 12.0 & 13.0 & 11.2 & 7.9 \\
\hline Respiratory, thoracic, or mediastinal & 2.3 & 1.0 & 1.7 & 2.9 \\
\hline Surgical wound & 1.3 & 2.5 & 2.5 & 2.4 \\
\hline Vascular & 5.7 & 3.9 & 4.2 & 10.3 \\
\hline \multirow[t]{2}{*}{ Cancer』 } & 0.5 & 0.7 & 1.0 & 2.1 \\
\hline & \multicolumn{4}{|c|}{ number of patients } \\
\hline Oral mucosa & 1 & 0 & 0 & 1 \\
\hline Kaposi's sarcoma & 1 & 1 & 0 & 0 \\
\hline Prostate & 0 & 0 & 1 & 0 \\
\hline Transitional-cell & 0 & 1 & 0 & 0 \\
\hline Renal-cell & 0 & 1 & 2 & 1 \\
\hline \multicolumn{5}{|l|}{ Lung } \\
\hline Non-small-cell & 0 & 0 & 0 & 1 \\
\hline Small-cell & 0 & 0 & 0 & 1 \\
\hline Breast & 0 & 0 & 0 & 1 \\
\hline Colon & 0 & 0 & 0 & 1 \\
\hline Cerebral lymphoma & 0 & 0 & 1 & 0 \\
\hline \multicolumn{5}{|l|}{ Non-Hodgkin's lymphoma } \\
\hline T-cell & 0 & 0 & 0 & 1 \\
\hline B-cell & 0 & 0 & 0 & 1 \\
\hline $\begin{array}{l}\text { Post-transplantation lymphoproliferative } \\
\text { disorder }\end{array}$ & 0 & 0 & 0 & 1 \\
\hline \multicolumn{5}{|l|}{ Skin } \\
\hline Basal-cell & 2 & 1 & 3 & 0 \\
\hline Squamous-cell & 1 & 0 & 1 & 0 \\
\hline Ovarian & 0 & 0 & 0 & 1 \\
\hline
\end{tabular}

The New England Journal of Medicine 


\begin{tabular}{|c|c|c|c|c|}
\hline \multicolumn{5}{|l|}{ Table 3. (Continued.) } \\
\hline \multirow[t]{2}{*}{ Event } & $\begin{array}{l}\text { Standard-Dose } \\
\text { Cyclosporine } \\
(N=384)\end{array}$ & $\begin{array}{l}\text { Low-Dose } \\
\text { Cyclosporine } \\
(\mathrm{N}=408)\end{array}$ & $\begin{array}{c}\text { Low-Dose } \\
\text { Tacrolimus } \\
(\mathrm{N}=403)\end{array}$ & $\begin{array}{c}\text { Low-Dose } \\
\text { Sirolimus } \\
(N=380)\end{array}$ \\
\hline & \multicolumn{4}{|c|}{ percent } \\
\hline \multicolumn{5}{|l|}{ Kaplan-Meier estimate of selected events $\emptyset$} \\
\hline $\begin{array}{l}\text { New-onset diabetes after transplantation } \\
\qquad(P=0.02)\end{array}$ & 6.4 & 4.7 & 10.6 & 7.8 \\
\hline Use of antidiabetes medication $(P=0.37) \|$ & 1.3 & 1.5 & 2.7 & 1.0 \\
\hline Diarrhea $(P<0.001)$ & 17.9 & 14.4 & 27.4 & 24.0 \\
\hline Lymphocele formation $(P<0.001) * *$ & 7.0 & 6.8 & 4.0 & 15.8 \\
\hline Opportunistic infection $(P=0.03)$ & 33.0 & 28.1 & 26.3 & 26.6 \\
\hline Cytomegalovirus $(P=0.003)$ & 15.3 & 11.5 & 10.2 & 6.5 \\
\hline \multicolumn{5}{|c|}{ 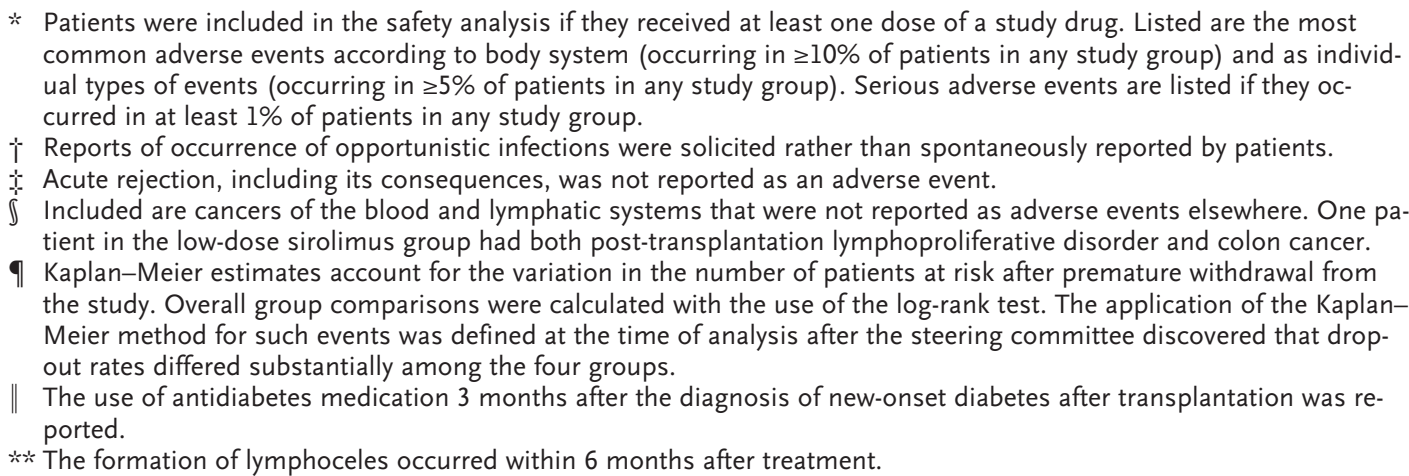 } \\
\hline
\end{tabular}

lated to the use of immunosuppressive drugs that impair glucose tolerance, such as tacrolimus and corticosteroids. Given the superior rates of biopsy-proven acute rejection associated with the tacrolimus regimen in our study, it may be possible to reduce the risk of new-onset diabetes after transplantation further by a reduction in the exposure to corticosteroids. For example, in a 6-month trial involving 538 renal-transplant recipients, those receiving tacrolimus, mycophenolate mofetil, and daclizumab had a significantly lower incidence of new-onset diabetes after transplantation than did those receiving tacrolimus, mycophenolate mofetil, and corticosteroids $(0.4 \%$ vs. $5.4 \%, \mathrm{P}=0.003) .{ }^{21}$

In conclusion, in our study involving kidneytransplant recipients, treatment for 12 months with a regimen containing daclizumab, mycophenolate mofetil, corticosteroids, and low-dose tacrolimus provided adequate immunosuppression with better renal function and less acute rejection, as compared with daclizumab induction plus lowdose cyclosporine or low-dose sirolimus-contain- ing regimens or to a regimen containing standarddose cyclosporine without daclizumab induction. In addition, the low-dose tacrolimus regimen provided better allograft survival than did regimens with standard-dose cyclosporine or low-dose sirolimus.

\section{Supported by Hoffmann-La Roche.}

Dr. Ekberg reports receiving consulting fees from HoffmannLa Roche, Novartis, Wyeth, and Astellas and lecture fees from Hoffmann-La Roche and Astellas; Dr. Tedesco-Silva, consulting and lecture fees from Novartis and grant support from Novartis, Wyeth, and Astellas; Dr. Vítko, consulting fees from Astellas, Wyeth, and Ivax Pharmaceuticals and lecture fees from Wyeth, Astellas, and Hoffmann-La Roche; Dr. Nashan, consulting fees from Viron, Hoffmann-La Roche, Novartis, Wyeth, Fujisawa Pharmaceutical, and Astellas, lecture fees from Novartis, Hoffmann-La Roche, and Wyeth, and grant support from CFI, Novartis, and the Nova Scotia Health Research Foundation; Dr. Margreiter, lecture fees from Hoffmann-La Roche; Dr. Hugo, consulting fees from Wyeth, lecture fees from Wyeth, Hoffmann-La Roche, and Johnson \& Johnson, and grant support from Wyeth, Novartis, German Research Foundation, and Interdisciplinary Center of Clinical Research; Dr. Grinyó, lecture and consulting fees from Hoffmann-La Roche; Dr. Frei, consulting and lecture fees from Hoffmann-La Roche and Novartis; Dr. Vanrenterghem, consulting fees from Janssen-Cilag, lecture fees from Hoffmann-La Roche and Astellas, and grant support from Amgen, Astellas, Baxter International, and Novartis; Dr. Hal- 
loran, holding two provisional patents on tissue rejection, receiving consulting and lecture fees from Roche and grant support from Roche Molecular Systems, Alberta Innovation and Science, and Genome Canada. No other potential conflict of interest relevant to this article was reported.

We thank Christa Silberbauer, the ELITE-Symphony project leader, for her great contributions to the study; Corrado Bernasconi for providing statistical support; Peter Wijngaard, Jana Nöldeke, and Carolyn Sutter, representatives of Hoffmann-La
Roche, for their support; Richard Glover of Wolters Kluwer Health for assistance in the preparation of the manuscript; Peter Morris, Daniel Abramowicz, and Gerhard Opelz (chair) of the data and safety monitoring board; and the study investigators and coordinators from the 15 participating countries (Australia, Austria, Belgium, Brazil, Canada, Czech Republic, Germany, Greece, Israel, Mexico, Poland, Spain, Sweden, Turkey, and the United Kingdom) for all their hard work in making this study possible.

\section{APPENDIX}

Investigators who participated in the ELITE-Symphony study are as follows: Australia: R. Walker, F. Ierino, G. Russ, J. Eris, P. O'Connell; Austria: F. Mühlbacher, R. Margreiter; Belgium: Y. Vanrenterghem, P. Peeters, N. Lameire; Brazil: D. Carvalho, V. Garcia, R. Esmeraldo, H. Tedesco-Silva, L. Saber, G. Majella, G. Alves Filho, R. Gonçalves; Canada: S. Gourishankar, P. Daloze; Czech Republic: V. Treska, J. Dedochová, M. Kuman, P. Navrátil, S. Vítko; Germany: U. Frei, M. Büchler, M. Wiesel, L. Fricke, H.-H. Neumayer, E. Nagel, W. Arns, F. Pietruck, C. Hugo, M. Ketteler, V. Kliem, R. Viebahn, J. Klempnauer, B. Nashan, H. Wolters, C. Krieglstein, U. Ott; Greece: J. Boletis, D.N. Takoudas, A. Antoniadis; Israel: M. Shabtai, A. Yussim, S. Mizrahi, R. Ramadan, R. Nakache, E. Ahmed; Mexico: R. Reyes Acevedo, M. Barrón, R. Salinas-González; Poland: M. Durlik, M. Klinger; Spain: J.M. Grinyó, M. Arias, J.M. Morales, F. Oppenheimer, J. Sanchez-Plumed, I. Lampreave, F. Valdés, M. Ángel Gentil, G. Rodríguez, A. Osuna, D. Hernandez, M. Tabernero, F. Anaya, F. Ortega, M. Rivero Sánchez, R. Marcen, M. Gonzalez-Molina, R. Lauzurica; Sweden: H. Ekberg, L. Mjörnstedt; Turkey: A. Uğur Yalçın, E. Ok, E. Akoglu, A. Gürkan, A. Demirbaş, M. Şükrü Sever, M. Yenicesu, O. Oymak, U Erken, B. Erbay, K. Dilek, I. Titiz; United Kingdom: R. Chavez, M.L. Nicholson.

\section{REFERENCES}

1. Pascual M, Theruvath T, Kawai T, Tolkoff-Rubin N, Cosimi AB. Strategies to improve long-term outcomes after renal transplantation. N Engl J Med 2002;346: 580-90.

2. Burdmann EA, Andoh TF, Yu L, Bennet WM. Cyclosporine nephrotoxicity. Semin Nephrol 2003;23:465-76.

3. Curtis JJ. Hypertensinogenic mechanism of the calcineurin inhibitors. Curr Hypertens Rep 2002;4:377-80.

4. Idem. Hypertension following kidney transplantation. Am J Kidney Dis 1994;23: 471-5.

5. Kobashigawa JA, Kasiske BL. Hyperlipidemia in solid transplantation. Transplantation 1997;63:331-8.

6. Luke RG. Mechanism of cyclosporineinduced hypertension. Am J Hypertens 1991;4:468-71.

7. Nankivell BJ, Borrows RJ, Fung CL, O'Connell PJ, Chapman JR, Allen RD. Calcineurin inhibitor nephrotoxicity: longitudinal assessment by protocol histology. Transplantation 2004;78:557-65.

8. Webster AC, Woodroffe RC, Taylor RS, Chapman JR, Craig JC. Tacrolimus versus ciclosporin as primary immunosuppression for kidney transplant recipients: metaanalysis and meta-regression of randomised trial data. BMJ 2005;331:810.

9. Margreiter R. Efficacy and safety of tacrolimus compared with ciclosporin microemulsion in renal transplantation: a ran- domised multicentre study. Lancet 2002; 359:741-6.

10. Sperschneider H. A large, multicentre trial to compare the efficacy and safety of tacrolimus with cyclosporine microemulsion following renal transplantation. Transplant Proc 2001;33:1279-81.

11. Groth CG, Bäckman L, Morales JM, et al. Sirolimus (rapamycin)-based therapy in human renal transplantation: similar efficacy and different toxicity compared with cyclosporine. Transplantation 1999;67:103642.

12. Kreis H, Cisterne JM, Land W, et al. Sirolimus in association with mycophenolate mofetil induction for the prevention of acute graft rejection in renal allograft recipients. Transplantation 2000;69: 1252-60.

13. Dean PG, Lund WJ, Larson TS, et al. Wound-healing complications after kidney transplantation: a prospective, randomized comparison of sirolimus and tacrolimus. Transplantation 2004;77:1555-61.

14. Langer RM, Kahan BD. Incidence, therapy, and consequences of lymphocele after sirolimus-cyclosporine-prednisone immunosuppression in renal transplant recipients. Transplantation 2002;74:804-8.

15. Rosengard BR, Feng S, Alfrey EJ, et al. Report of the Crystal City meeting to maximize the use of organs recovered from the cadaver donor. Am J Transplant 2002;2:701-11.
16. Cockcroft DW, Gault MH. Prediction of creatinine clearance from serum creatinine. Nephron 1976;16:31-41.

17. Vincenti F, Ramos E, Brattstrom C, et al. Multicenter trial exploring calcineurin inhibitors avoidance in renal transplantation. Transplantation 2001;71:1282-7.

18. Ekberg H, Grinyó J, Nashan B, et al. Cyclosporine sparing with mycophenolate mofetil, daclizumab and corticosteroids in renal allograft recipients: the CAESAR Study. Am J Transplant 2007;7: 560-70.

19. Flechner SM, Kurian SM, Solez K, et al. De novo kidney transplantation without use of calcineurin inhibitors preserves renal structure and function at two years. Am J Transplant 2004;4:1776-85.

20. Association of a Rapamune (sirolimus) containing immunosuppressant regimen with a high rate of acute rejection in de novo renal transplant patients. Markham, ON, Canada: Wyeth Pharmaceuticals, August 18, 2006. (Accessed November 21, 2007 at: http://www.hc-sc.gc.ca/dhp-mps/medeff/ advisories-avis/prof/2006/rapamune_3_ hpc-cps_e.html.)

21. Rostaing L, Cantarovich D, Mourad $\mathrm{G}$, et al. Corticosteroid-free immunosuppression with tacrolimus, mycophenolate mofetil, and daclizumab induction in renal transplantation. Transplantation 2005; 79:807-14.

Copyright (c) 2007 Massachusetts Medical Society. 